\title{
Patients' perspectives on foot complications in type 2 diabetes: a qualitative study
}

\author{
Lone Gale, Kavita Vedhara, Aidan Searle, Terry Kemple and Rona Campbell
}

\begin{abstract}
Background

Foot ulceration is a major health problem for people with diabetes. To minimise the risk of ulceration, patients are advised to perform preventive foot self-care.
\end{abstract}

Aim

To explore beliefs about diabetic foot complications and everyday foot self-care practices among people with type 2 diabetes.

Design of study

Qualitative study using one-to-one interviews.

Setting

A suburban primary care health centre.

Method

Semi-structured interviews with a purposive sample of adults with type 2 diabetes but with no experience of foot ulceration.

Results

Most participants were unsure of what a foot ulcer is and unaware of the difficulties associated with ulcer healing. Prevention of accidental damage to the skin was not considered a priority, as few participants knew that this is a common cause of foot ulceration.

Although it was recognised that lower-limb amputation is more common in people with diabetes, this was perceived to be predominantly caused by poor blood supply to the feet and unrelated to foot ulceration. Therefore, preventive foot care focused on stimulating blood circulation, for example by walking barefoot. Consequently, some of the behaviours participants considered beneficial for foot health could potentially increase the risk of ulceration. In some cases the uptake of advice regarding preventive foot care was hampered because participants found it difficult to communicate with health professionals.

\section{Conclusion}

Patients with type 2 diabetes may have beliefs about foot complications that differ from medical evidence. Such illness beliefs may play a role in foot-related behaviours that have previously been unrecognised. Health professionals need to explore and address the beliefs underlying patients' foot self-care practices.

\section{Keywords}

diabetes mellitus; foot complications; foot self-care; illness beliefs; ulcer prevention.

\section{INTRODUCTION}

Ulceration of the foot is a serious problem for people with diabetes. In the UK approximately one in six people with diabetes develop foot ulcers at some stage in their lives. ${ }^{1}$ Outcome of foot ulceration is often poor: healing is slow, a high proportion of ulcers do not heal in spite of intensive treatment, ${ }^{2-4}$ and up to $17 \%$ of foot ulcers result in minor or major amputation..$^{3-6}$ Treatment of diabetic foot complications is a major financial burden on the healthcare system. ${ }^{7-8}$

Foot ulcers are, in most cases, caused by a combination of risk factors associated with chronic complications of diabetes. ${ }^{9,10}$ These include long-term hyperglycaemia, which can lead to microvascular disease that damages the small blood vessels and causes malfunctioning of the nerves. The most common form is distal symmetrical neuropathy that results from the dying back of axons in the longest nerves, thereby affecting the feet first. Symptoms include insensitivity to pain, burning sensations, muscle wasting, and foot deformity. People with diabetes are also at high risk of developing macrovascular disease, particularly if they smoke or have hypertension or hyperlipidaemia. Macrovascular disease affects the large blood vessels and can lead to peripheral vascular disease and reduced blood supply to the legs and feet. Many people with diabetes have both conditions. ${ }^{9,10}$

L Gale, MSc, research student; $K$ Vedhara, $P h D, M R C$ programme leader; $A$ Searle, $P h D, M R C$ career development fellow; $\boldsymbol{R}$ Campbell, PhD, professor of health services research, Department of Social Medicine, University of Bristol; T Kemple, FRCP, FRCGP, DCH, GP, Horfield Health Centre, Horfield, Bristol.

Address for correspondence

Lone Gale, University of Bristol, Department of Social Medicine, Canynge Hall, 39 Whatley Road, Bristol, BS8 2PS. E-mail: Lone.Gale@bristol.ac.uk

Submitted: 4 January 2008; Editor's response: 11 March 2008; final acceptance: 24 June 2008.

OBritish Journal of General Practice.

This is the full-length article of an abridged version published in print. Cite this article as: BrJ Gen Pract 2008; DOI: 10.3399/bjgp08X319657 
Peripheral neuropathy and peripheral vascular disease are the main predisposing risk factors for foot ulceration because they render the feet vulnerable to skin damage. A foot ulcer is, in the vast majority of cases, the consequence of interaction between predisposing risk factors (for example, loss of sensation due to peripheral neuropathy, or dry, fragile skin due to peripheral vascular disease) and precipitating factors linked to the person's foot-related behaviours (for example, penetration of the dermis of the foot due to illfitting shoes) (Appendix 1). ${ }^{1,10,11}$ A person affected by neuropathy may not feel the pain or discomfort that should draw attention to the problem. Repetitive trauma from unsuitable footwear and accidental injury to the dermis are the most common precipitating factors that lead to foot ulceration. ${ }^{10,12,13}$ In one major multicentre study, no predisposing risk factor was present in $10 \%$ of the UK participants and their foot ulcer was entirely due to accidental skin damage..$^{13}$

If the person suffers from peripheral vascular disease, tissue repair will be impeded, thereby extending the period of time that bacteria can enter through the dermis. Furthermore, due to diabetes, the immune system response may be impaired, making infection more likely, while peripheral vascular disease compounds the situation by reducing the efficacy of antibiotic medication. The vast majority of lower-limb amputations in people with diabetes are preceded by an infected, non-healing foot ulcer originating from a minor lesion. ${ }^{1,14}$ A simplified model of the pathway to amputation is provided in Appendix 2.

Once a person with diabetes has had one foot ulcer the likelihood of further episodes of ulceration is very high. $^{15,16}$ Therefore, primary prevention is extremely important. It has been suggested that up to half of all lower-limb amputations could be avoided with improved measures to prevent foot ulceration..$^{17,18}$ Consequently, to reduce the risk of ulceration, people with diabetes are encouraged to avoid behaviours that could cause a break in the skin on the feet and to perform daily preventive foot self-care, such as foot self-examination. ${ }^{11}$

Little is known about how people with diabetes and no history of foot ulceration actually care for their feet. A few surveys have concluded that most patients have insufficient knowledge about how to reduce the risk of ulceration. ${ }^{19,20}$ The supposition has generally been, therefore, that increasing the amount of advice and education would lead to improved self-care, although there is little empirical support for this approach. Systematic reviews of educational interventions for improved preventive foot self-care have found only short-term effects and no evidence of reduced incidence of ulceration..$^{21,22}$

There is general agreement among clinicians and researchers that patient behaviours play a significant

\section{How this fits in}

Clinicians and researchers have suggested that the incidence of diabetic foot ulceration could be substantially reduced with improved patient foot self-care.

It was found that the majority of the participants had beliefs about foot

complications and foot self-care practices that could potentially increase, rather

than decrease, the risk of ulceration; therefore, health professionals need to be

aware that patients may have perceptions or concerns about foot health that are

very different from their own. It is important that healthcare staff create

opportunities within consultations to explore and, where necessary, challenge,

patients' beliefs about the causes and prevention of foot complications. They

should also ensure that their advice is tailored to take account of patients' beliefs.

role in foot ulceration, particularly in relation to footwear. Wearing badly designed footwear that cause sores, or unsuitable footwear that gives little or no protection against accidental injuries are major precipitating factors of foot ulceration in people with diabetes..$^{10,12,23}$ However, the main considerations that guide people with diabetes in their foot-related behaviours are not known. Although a few studies have investigated the topic among patients with a history of foot ulceration, ${ }^{24}$ there has been no study of patients who have never had an ulcer. Consequently, the aims for this study were to explore beliefs about diabetic foot complications and everyday foot selfcare practices in people with type 2 diabetes who had no experience of foot ulcers or professionally-treated foot wounds since diagnosis.

\section{METHOD}

Given the exploratory nature of the study, a qualitative methodology was chosen. To take account of the possibility that there might be important differences between patients with type 1 and type 2 diabetes of relevance to foot health, participation was limited to adults with type 2 diabetes.

A purposive sample was recruited from a large primary care health centre which serves a suburban population that is predominantly white. The catchment area includes both affluent neighbourhoods and areas of deprivation. The Index of Multiple Deprivation Score is reported to be 29.9 which, overall, indicates a medium level of deprivation. A maximum variation sampling strategy was used to achieve a good spread in terms of sex, age, duration of diabetes, and method of control. Table 1 provides demographic details of the 18 study participants.

Semi-structured, face-to-face in-depth interviews were conducted by a researcher who informed participants that she had no medical background. Most interviews were conducted in the participants' homes and lasted between 60 and 90 minutes. The researcher followed a topic guide that had been developed on the basis of pilot interviews (not 


\begin{tabular}{|c|c|}
\hline & Participants, $n$ \\
\hline \multicolumn{2}{|l|}{ Age, years ${ }^{a}$} \\
\hline$\leq 49$ & 3 \\
\hline $50-59$ & 2 \\
\hline $60-69$ & 6 \\
\hline$\geq 70$ & 7 \\
\hline \multicolumn{2}{|l|}{ Sex } \\
\hline Female & 9 \\
\hline Male & 9 \\
\hline \multicolumn{2}{|l|}{ Ethnicity } \\
\hline White British & 16 \\
\hline Asian & 1 \\
\hline Black-African & 1 \\
\hline \multicolumn{2}{|c|}{ Time since diagnosis, years ${ }^{b}$} \\
\hline$<2$ & 5 \\
\hline $2-9$ & 9 \\
\hline $10-19$ & 3 \\
\hline$\geq 20$ & 1 \\
\hline \multicolumn{2}{|c|}{ Mode of diabetes control } \\
\hline Diet only & 1 \\
\hline Diet and tablets & 11 \\
\hline Diet and insulin & 6 \\
\hline
\end{tabular}

included in this sample). As well as questions relating to diabetes, topics included beliefs about the causes and prevention of foot complications, everyday footrelated behaviours, information/advice received about foot health, and views regarding healthcare provision.

All interviews were tape-recorded and transcribed verbatim. The method of constant comparison was used to analyse the data. ${ }^{25}$ Each transcript was read repeatedly and coded to identify emerging themes (no computer-assisted qualitative data analysis software was used). These were compared with other themes within each transcript and across all transcripts. The primary analysis was carried out and regularly discussed among the researchers. Transcripts were independently coded and a list of emerging themes and categories was drafted. These were compared and combined with those generated by the primary analysis and a coding frame was developed. During the fourth batch of interviews no new themes or categories were found and data saturation was considered to have been reached. Emerging themes, descriptive accounts, and interpretation of the data were discussed frequently among the researchers. Furthermore, work in progress was presented and discussed at the annual MRC Chronic Wounds Programme meetings.

\section{RESULTS}

The in-depth interviews yielded data on many topics; three of the major themes are reported on here:
- beliefs about foot ulceration and causes of amputation;

- relationship between beliefs and foot-related behaviours; and

- communication with health professionals.

\section{Beliefs about foot ulceration and causes of amputation}

Being diagnosed with diabetes meant there was a great amount of information to take in and, as a result of this, participants tended to push foot-care advice into the background:

'I had been told at the surgery [that foot care was very important] but I hadn't sort of ... you know how they go on about, they go on about your diet, they go on about your cholesterol, they go on and you think, "Oh it's just another thing", you know.' (Mrs Q, aged 62 years)

Often it was hearing about other peoples' foot problems that alerted participants to the possibility of complications:

'Well, I suppose it's hearing about our neighbour having to have three toes off. Makes me a bit more conscious of the fact that l've got to look after them.' (Mrs P, aged 72 years)

As highlighted by one responder, very few participants thought there was a relationship between glycaemic control and foot complications:

'About her [sister with diabetes], she was not taking her medicine properly and so her sugar level wasn't controlled and one of her legs was amputated.' ( $\mathrm{Mr} \mathrm{H}$, aged 50 years)

Most of the participants expressed uncertainty about what a foot ulcer is and its cause:

'Well, I'm not sure to be honest, I couldn't describe it, not really. No, I'm not entirely sure what they're talking about, how to describe it.' (Mr O, aged 67 years)

I should think it would more or less, um, come up like a white spot and go to something like a boil. Something like that on the foot.' (Mrs K, aged 78 years)

Only two out of the 18 participants were aware that a foot ulcer is a sore or wound on the foot of a person with diabetes:

Interviewer (l): '... what is a foot ulcer?' 
Participant (P): 'It's a break in the foot, in the skin, I suppose.'

I: 'Any break in the skin?'

P: 'Yeah.' (Mr G, aged 78 years)

'A sore is the same thing as an ulcer.' (Mrs P, aged 72 years)

Despite uncertainty about what exactly foot ulcers are, the general perception was that they could be treated and cured. Similarly, the majority of participants did not expect difficulties with the healing of cuts, sores, or blisters on the feet:

I: 'In the information you have had about diabetes and foot health, has there been anything about foot ulcers?'

P: 'Yes, um obviously that if that happens then to consult the chiropodist straight away and you will be seen straight away and it will be sorted for you ... I mean I wouldn't go round for a blister or something like that. I would try and treat that myself and then if it didn't clear up after a couple of days then I would go and seek help then for it.' (Miss $\mathrm{R}$, aged 44 years)

Only in the case of lack of proper care, for example poor foot hygiene, was it was thought likely that a minor injury or foot ulcer could lead to amputation:

'Well, l'd say, one doesn't like to be critical ... maybe he [acquaintance who had his toe amputated] is not as particular about sort of keeping himself clean, I don't know.' (Mr I, aged 69 years)

'And then, I mean, years ago diabetics had to have toes and feet and legs and things amputated, didn't they? Which apparently does still happen if people don't look after their feet.' (Mrs S, aged 59 years)

There was great variation in participants' selfreported foot care, ranging from wiping feet with surgical spirit to not washing the feet on a daily basis. However, all participants perceived their own foot hygiene to be adequate, while sometimes taking the view that other people put less effort into it:

P: 'Well, the bottom line, really, has always been cleanliness and I think that's very important where feet are concerned and particularly diabetic feet as well. So yes, that rates as very important to me. And I think that if people made the stipulation that they spent 10 minutes every day doing their feet it would save an awful lot of problems.'
I: 'You think it would avoid a lot of foot problems?'

P: 'I think it would.' (Mrs P, aged 72 years)

Many participants were aware that amputations are much more common in people with diabetes. Participants' responses during the interviews indicated that most held beliefs regarding lower-limb complications that appeared to differ from the medical evidence as described in the introduction and illustrated in Appendix 2. The main cause of amputation was believed to be peripheral vascular disease but without the involvement of skin damage and infection. The perception was that poor blood circulation alone would lead to the destruction of nerves and tissue in the feet. Foot symptoms, such as loss of sensation or burning sensations, which many had been told were due to 'nerve damage', were interpreted as the result of circulatory problems:

I: 'Why do you think it is that diabetes can affect the feet?'

P: 'The circulation goes, doesn't it? Well, I think it's the circulation. Because you do get like ... I have got some, some of my toes, I haven't got much feeling in ...'

I: 'So you think the fact that you've got slightly numb toes is because the circulation isn't quite getting into your toes?'

P: 'I think so.'

I: 'What could be the effect of having numb toes?'

P: 'Well, if the blood doesn't get there and you're not looking after them you can get like my cousin and you can get gangrene.' (Mrs $\mathrm{Q}$, aged 62 years)

I: 'What could be the risk to your feet from numbness?'

P: 'Well that to me is a sign of bad circulation. If you stop getting a decent flow then eventually something is going to wither and die. So it's sort of quite important to keep the circulation going if you can.'

I: 'So do you view that [numbness] as the first symptom of poor circulation?'

P: 'Yeah.' (Mr F, aged 43 years)

The fact that most of the participants subscribed to the belief that poor blood supply alone was the root cause of foot symptoms often resulted in misinterpretation of explanations and feedback from health professionals. For example, in spite of being informed that tests were to assess sensation in the feet, participants nevertheless made the assumption that they were really to test the blood circulation:

I: 'Do they tell you what the [foot] tests are for?'

P: 'No, they just tell you that they're checking for, 
you know, to see how sensitive your feet are and that. But it's obvious they're just checking to see whether the circulation's getting down that far.' (Mrs Q, aged 62 years)

Participants who had been diagnosed with nerve damage were particularly worried that the condition might get progressively worse and eventually necessitate amputation:

'It worries me really, because you hear of people losing their legs and their feet. Well, I assume it starts from ... well, I don't know whether it [numbness and discomfort] can go any worse and go up my leg. It don't go no further than my ankle, but l've never questioned the doctor. I've never said anything to him, but I don't know whether it does go up your leg. Is that how they lose their legs?' (Mr D, aged 69 years)

Nerve damage and symptoms such as numbness or discomfort were interpreted as a consequence of reduced blood circulation. Participants believed the main cause of amputation was poor blood circulation leading to gangrene; foot injuries and ulcers, on the other hand, were only thought to lead to amputation in rare cases when some kind of neglect had occurred (for example, poor hygiene or delayed treatment). Participants' beliefs are illustrated in Appendix 3.

These beliefs differ from medical evidence, which points to a break in the skin, reduced healing potential due to vascular disease, and infection as the crucial factors in amputation. It would appear that because participants focused, sometimes exclusively, on blood circulation (rather than ulceration) as a cause of amputation, this adversely affected their foot-related behaviours and communication with health professionals.

\section{Relationship between beliefs and foot-related behaviours}

From a medical perspective, the most important aspects of foot care for people with diabetes are prevention of skin damage and prompt professional treatment of any break in the skin. ${ }^{11}$ However, the majority of participants in the current study expected a sore or cut on a foot to heal normally without medical treatment:

I: 'What do you think could happen if for instance you cut your toe on something sharp?'

P: 'Well, I would expect it to just heal up again I think. Obviously you'd need to sort of keep an eye on it, keep it checked, you know.' (Mrs C, aged 73 years)
Instead, participants were concerned about preventing the blood supply to their feet from becoming restricted. The general belief was that physical manipulation, either by exercising or massaging the feet, could stimulate the blood flow:

I: 'Do you think your hands and fingers might be at risk [of poor blood supply]?'

P: 'Yeah, but you tend to, you've got more movement, you know what I mean, and your hands and your fingers are moving all the time, whereas your feet, they're really, I mean especially if you're inactive ... You know, your toes and your feet are not actually moving that much unless you're walking and I mean with your hands, you're manipulating things all the time.'

I: 'So do you sometimes sit in the evenings and take your shoes off and move your toes?'

P: 'All the time.'

I: 'You do?'

P: 'Um, well when I say move my toes, I'll sit there, I'll sit in the corner, I'll lift my leg up and I'll just massage my foot, you know.' (Mr F, aged 43 years)

'I haven't never been told that, but I do sit here every night with no socks on and try and move my toes and that. I do that every night practically, but the toes are so stiff.' (Mr D, aged 69 years)

Wearing open-toed sandals (with socks, in the winter) or buying footwear a size too large was also believed to give the toes space to move, and a common practice among participants:

'I'd go for a size bigger, you know. That's what I tend to do with everything on my feet. I always tend to buy anything bigger. I take a 9 normally, but I buy 10 because it gives me that extra room.' (Mr $\mathrm{D}$, aged 69 years)

Furthermore, half the sample said that they would regularly walk around without footwear in an attempt to keep the joints flexible and the circulation going. Some participants were aware that this behaviour was at odds with practitioner advice:

I: 'If you're at home, what do you wear on your feet?'

P: 'Well, I'm terrible for going round in bare feet.'

I: 'Why do you say that's terrible?'

P: 'Well, they say "You've got to watch your feet, so don't go without in case you step on anything", you know. And they're right, I suppose, really.' (Mr $\mathrm{O}$, aged 67 years)

Most of the participants appeared to engage in behaviours that could actually increase the risk of skin 
damage and ulceration, on the assumption that it would improve the blood circulation. Although the risk of minor foot injuries was recognised this was not considered of particular consequence, as an 'ordinary' lesion was not considered worse for someone with diabetes compared to someone without diabetes:

I: 'Is it a problem that you wear open-toe sandals? I'm thinking in terms of maybe accidentally stubbing your toes.'

P: 'Well, sometimes you're lucky that you don't [laughs]. Um, yeah there is a chance, but then that's a chance I suppose I take. Well, I suppose it's like anybody if they knocked their toes, you'd have to have it seen to, l'd have to go and have it seen to, wouldn't I, or see to it myself or something.' (Mrs M, aged 62 years)

Many of the participants mentioned that they had numb areas on their feet. However, there was a general lack of awareness that this might affect sensation:

I: 'Do you sometimes put your hand inside your shoes to make sure there's nothing loose in there?' P: 'No, I don't, that's the sort of thing I never think about, to be honest.'

I: 'No? Or that there's no grit inside them?'

P: 'Well, if there's grit, surely you can feel it, of course.' (Mr O, aged 67 years)

Many participants had been advised to examine their feet regularly, but the purpose of this was not always clear:

'It's a load of old tosh isn't it? What would I want to check them [feet] every morning for?' (Mr J, aged 70 years)

\section{Communication with health professionals}

Most participants reported some difficulty communicating with health professionals about foot health and were often left feeling confused:

'They did explain it [result of foot tests] to me but I couldn't ... he said "You see, that's like that" and I was like "Yeah ..." and I thought "No I don't really, but never mind [laughs], you're the expert".' (Mrs $\mathrm{S}$, aged 59 years)

Nevertheless, even though explanations were often difficult to comprehend, many participants appeared to have complete trust in health professionals and tried to adhere to advice on the assumption that there must be a good reason for it. They tended to doubt their own competence and sought reassurance from health professionals. Regular check-ups with a podiatrist provided such reassurance, but only half of the sample had access to this service:

'I do feel I'm in good hands, they're very good indeed. Although I check as much as I can, and I'm quite thorough really, it is good to have somebody else, who knows what they're doing, having a look at a regular basis. I'm just grateful for what they do, because hopefully it's all for my benefit.' (Mr I, aged 69 years)

Although they trusted health professionals, participants sometimes decided to ignore advice, but were then left feeling that they were being 'naughty':

'They told me I mustn't walk round without shoes on and I'm very naughty, because I do.' (Mrs S, aged 59 years)

'They said you should really always wear shoes or slippers. Naughty girl that I don't.' (Mrs P, aged 72 years)

Other participants were somewhat disaffected with health professionals. Some felt they were not given adequate explanations for foot problems or that health professionals were not sufficiently interested in foot health:

I: 'Weren't you told anything about what caused it [pain in feet]?'

P: 'No, that's all he said "nerve endings". I wish I knew why it was, I don't. The doctor don't sound very interested so ... it's square one again, isn't it?' (Mr J, aged 70 years)

I would say, actually, if I'm honest with you, the feet side of things is something that always gets ignored. If your doctor and your nurse don't prioritise it, why should you?' (Mr F, aged 43 years)

Participants mentioned that foot checks were sometimes not carried out at the annual diabetes review:

'They [nurses] do all the checks every time, yeah. Sometimes they forget to do your feet.' (Mr G, aged 78 years)

Additionally, they commented that health professionals sometimes did not believe they had the symptoms they were reporting:

'She [GP] said "Oh, it's your arthritis". I said "It's not, please". "Oh yes, you've had it for years, there's nothing you can do, so it's probably that". 
And I said "It's a different pain, it's different, I know it's different". Which it was, it turned out, when I seen somebody else, that it was [neuropathy].' (Mrs M, aged 62 years)

In a few cases, communication seemed very poor:

'Every time / see [the GP] he's got his computer on down there and he don't look at eyes, he's looking at the computer all the time. It's just like talking to the wall. So I don't bother any more.' (Mr J, aged 70 years)

It was clear that participants who reported difficulties communicating with health professionals were more likely to ignore foot-care advice and, instead, rely on what they considered to be common sense.

\section{DISCUSSION}

\section{Summary of main findings}

In this sample of people with type 2 diabetes and no history of foot ulceration, the majority had no clear awareness of what foot ulceration is or of common obstacles to successful treatment. Consequently, they did not appreciate the potential seriousness of a break in the skin on a foot. Instead, the general perception was that reduced blood supply to the feet was the primary cause of foot complications in diabetes. Therefore the participants' model of the typical pathway to lower-limb amputation differed from the medical model. This seemed to be associated with potentially negative consequences in many ways.

Most participants had foot-related practices that they believed to be beneficial but that could, paradoxically, increase the risk of ulceration. There was also a considerable amount of confusion and uncertainty among the participants and many reported difficulty understanding health professionals' explanations or advice. Additionally, participants often felt they had a dilemma: they did not know whether to adhere to advice they did not see the purpose of, or to follow their own beliefs about the best way to care for their feet. The relationship with health professionals was in some cases strained. The divergent, but possibly not explicit, views about foot health may have contributed to this.

\section{Strengths and limitations of the study}

The strength of qualitative research has been described as its ability to 'reach the part other methods cannot reach', ${ }^{26}$ namely the views and experiences of ordinary people. Accordingly, the aim of qualitative research is often to penetrate participants' socially acceptable public accounts and to access their private accounts and their real views. ${ }^{27}$ This was largely achieved, as evidenced by the fact that many participants divulged beliefs and behaviours that appeared to go against medical advice.

However, there are limitations to this study: the data originate from a single, in-depth interview with 18 patients. Further work, in focus groups for example, could have added to the richness of the data. As such, the findings of this exploratory study cannot be generalised but, given the lack of available research in this area, the study provides important insights. A further limitation is that the patients' perspectives could not be related to those of the relevant health professionals. Future research would benefit from examining both.

The interviewed sample was relatively well balanced in terms of demographic and diabetes-related variables and, although it reflected the population in the health centre's catchment area, where $86 \%$ are described as white British, minority ethnic groups were under-represented. Previous studies have shown differences in diabetes-related beliefs and behaviours among different ethnic groups, even those living within the same community, ${ }^{28-30}$ so further studies are needed to examine the issue of beliefs about foot health and self-care practices within a variety of cultural settings.

\section{Comparison with existing literature}

This particular study is, to the authors' knowledge, the first to investigate perceptions of foot complications among people with type 2 diabetes who do not have personal experience of ulceration. Previous studies have assessed patients' knowledge of the medical model of diabetic foot complications and adherence to recommended foot self-care behaviours; in general, these studies reveal that knowledge is inadequate and adherence is low. ${ }^{19,20}$

A recent qualitative study of 22 patients with neuropathy reported that most interviewees did not know what a foot ulcer was, even those who had been treated for ulceration at a specialist diabetes foot clinic. $^{31}$ Furthermore, in that study none of the interviewees was aware of the main cause of foot ulceration, but blood circulation and neglect were frequently mentioned; the current findings correspond well with those findings.

This study sought to go beyond participants' footrelated knowledge to explore also the rationale on which patients based foot self-care behaviours. Taking participants' views as the starting point has enabled the proposal of a novel explanation for non-adherence to preventive foot-care advice in this patient group. Most participants had beliefs about the causes and prevention of diabetic foot disease that differed from current medical evidence. This observation is consistent with previous work, which has shown that patients with chronic disease often hold beliefs about 
the likely cause, course, and management of their condition that differ from the medical disease model. ${ }^{32-35}$ Medically unorthodox beliefs have also been observed in lay views of drugs and medicines. ${ }^{36}$

There were indications in this study that participants sometimes deliberately decided to disregard foot-care advice from professionals if it contradicted their personal beliefs (for example, in relation to sometimes walking barefoot). This corresponds to findings by Campbell et $a l,{ }^{37}$ who termed such an approach 'strategic non-compliance'.

Many participants in this study expressed dissatisfaction with the care they received in relation to foot health. A few previous studies have reported similar findings and that patients sometimes blame health professionals after foot ulceration has occurred. . $35,38^{2}$

It is a matter of concern that most participants in this study were unaware of the connection between breaks in the skin, foot ulceration, and amputation. There is good evidence that the single most important thing that can be done by people with diabetes particularly older people who are more likely to have developed micro- and macrovascular disease - to prevent foot ulceration is to protect their feet from any cuts, sores, blisters, or cracked skin..$^{10,11}$

Health professionals need to be aware that their patients may have views or concerns in relation to foot health that they do not volunteer in the clinical setting. Research concerning the management of diabetes and other medical conditions has shown that patients sometimes conceptualise their illness differently from practitioners..$^{32-34}$ Therefore, it has been suggested that health professionals should routinely try to elicit patients' beliefs about their condition. ${ }^{39-41}$ Misperceptions that might affect health outcomes may be detected and can then be addressed and treatment or self-management negotiated. In a recent quasi-experimental study, GPs received training for 6 hours in ways to elicit patients' illness beliefs. ${ }^{42}$ This brief training was found to lead to increased discussion of patients' views and concerns. Furthermore, it has been shown that health professionals trying to understand their patients' illness beliefs is associated with greater patient satisfaction. ${ }^{43}$ To achieve improved health outcomes, however, patients also need to be supported to become actively involved in decision making regarding the management of their condition. ${ }^{40,44}$

\section{Implications for clinical practice}

The current study indicates that many patients with type 2 diabetes hold beliefs about foot complications that differ somewhat from medical evidence. These beliefs may lead to the adoption of self-care behaviours that could potentially increase the risk of ulceration and, if not recognised, hamper effective communication between patients and health professionals. Therefore, it is important for health professionals to create opportunities within consultations to explore patients' beliefs about causes and prevention of foot complications. They should also ensure that their advice is tailored to take account of these beliefs. Specific points that health professionals may want to discuss with their patients to avoid common misconceptions about foot health and ulceration are suggested in Appendix 4.

To conclude, some patients with type 2 diabetes may disregard foot-care advice from health professionals because their beliefs about foot complications do not concur with the medical model. Unless this is addressed explicitly, patients may inadvertently increase their risk of developing a foot ulcer and initiate the process associated with recurring ulceration and amputation.

\section{Funding body}

This study was funded by a research studentship from the Medical Research Council (G78/8331) and supported by an MRC programme grant

\section{Ethical approval}

Ethics approval was granted by the United Bristol Health Care Trust Local Research Ethics Committee (05/Q2002/12)

\section{Competing interests}

The authors have stated that there are none

\section{Acknowledgements}

We would like to thank the participants for taking part in this study and the GPs who helped to recruit the participants. We would also like to thank the members of the MRC Chronic Wounds Programme for feedback to work in progress. Special thanks to research fellow Elizabeth Mudge (University of Cardiff), Dr Colin Dayan (University of Bristol), and senior podiatrist Edyth Dougan for their helpful comments on earlier drafts of this article.

\section{Discuss this article}

Contribute and read comments about this article on the Discussion Forum: http://www.rcgp.org.uk/bjgp-discuss

\section{REFERENCES}

1. Jeffcoate WJ, Harding KG. Diabetic foot ulcers. Lancet 2003; 361(9368): 1545-1551.

2. Kantor J, Margolis DJ. Expected healing rates for chronic wounds. Wounds 2000; 12(6): 155-158.

3. Pound N, Chipchase S, Treece K, et al. Ulcer-free survival following management of foot ulcers in diabetes. Diabet Med 2005; 22(10): 1306-1309.

4. Ismail K, Winkley K, Stahl D, et al. A cohort study of people with diabetes and their first foot ulcer: the role of depression on mortality. Diabetes Care 2007; 30(6): 1473-1479.

5. Oyibo SO, Jude EB, Tarawneh I, et al. The effects of ulcer size and site, patient's age, sex and type and duration of diabetes on the outcome of diabetic foot ulcers. Diabet Med 2001; 18(2): 133-138.

6. Moulik PK, Mtonga R, Gill GV. Amputation and mortality in newonset diabetic foot ulcers stratified by etiology. Diabetes Care 2003; 26(2): 491-494.

7. Davis WA, Norman PE, Bruce DG, Davis TM. Predictors, consequences and costs of diabetes-related lower extremity amputation complicating type 2 diabetes: The Fremantle Diabetes Study. Diabetologia 2006; 49(11): 2634-2641.

8. Matricali GA, Dereymaeker G, Muls E, et al. Economic aspects of diabetic foot care in a multidisciplinary setting: a review. Diabetes Metab Res Rev 2007; 23(5): 339-347. 
9. Williams G, Pickup JC. Handbook of diabetes. 3rd edn. Oxford: Blackwell Publishing, 2004.

10. Boulton AJM, Cavanagh PR, Rayman G (eds). The foot in diabetes. 4th edn. Chichester: John Wiley \& Sons, 2006.

11. National Institute for Clinical Excellence. Clinical Guideline 10. Type 2 diabetes. Prevention and management of foot problems. London: NICE, 2004.

12. Macfarlane RM, Jeffcoate WJ. Factors contributing to the presentation of diabetic foot ulcers. Diabet Med 1997; 14(10): 867-870.

13. Reiber GE, Vileikyte L, Boyko EJ, et al. Causal pathways for incident lower-extremity ulcers in patients with diabetes from two settings. Diabet Care 1999; 22(1): 157-162

14. Boulton AJ. The diabetic foot: from art to science. The 18th Camillo Golgi lecture. Diabetologia 2004; 47(8): 1343-1353.

15. Abbott CA, Carrington AL, Ashe H, et al. The North-West Diabetes Foot Care Study: incidence of, and risk factors for, new diabetic foo ulceration in a community-based patient cohort. Diabet Med 2002; 19(5): 377-384.

16. Crawford F, Inkster M, Kleijnen J, Fahey T. Predicting foot ulcers in patients with diabetes: a systematic review and meta-analysis. QJM 2007; 100(2): 65-86.

17. Anonymous. Diabetes care and research in Europe: the Saint Vincent declaration. Diabet Med 1990; 7(4): 360

18. Boulton AJ. Why bother educating the multi-disciplinary team and the patient - the example of prevention of lower extremity amputation in diabetes. Patient Educ Couns 1995; 26(1-3): 183-188.

19. Basu S, Hadley J, Tan RM, et al. Is there enough information about foot care among patients with diabetes? Int J Low Extrem Wounds 2004; 3(2): 64-68.

20. Pollock RD, Unwin NC, Connolly V. Knowledge and practice of foot care in people with diabetes. Diabetes Res Clin Pract 2004; 64(2): $117-122$.

21. Mason J, O'Keeffe C, McIntosh A, et al. A systematic review of foot ulcer in patients with Type 2 diabetes mellitus. I: prevention. Diabet Med 1999; 16(10): 801-812

22. Valk GD, Kriegsman DM, Assendelft WJ. Patient education for preventing diabetic foot ulceration. Cochrane Database Syst Rev 2001; 4: CD001488.

23. McGill M, Molyneaux L, Yue DK. Which diabetic patients should receive podiatry care? An objective analysis. Intern Med J 2005; 35(8): 451-456.

24. Hjelm K, Nyberg P, Apelqvist J. Gender influences beliefs about health and illness in diabetic subjects with severe foot lesions. J Adv Nurs 2002; 40(6): 673-684.

25. Charmaz K. Constructing grounded theory. A practical guide through qualitative analysis. London: Sage, 2006.

26. Pope C, Mays N. Reaching the parts other methods cannot reach: an introduction to qualitative methods in health and health services research. BMJ 1995; 311(6996): 42-45.

27. Murphy E, Dingwall R, Greatbatch D, et al. Qualitative research methods in health technology assessment: a review of the literature. Health Technol Assess 1998; 2(16): iii--ix.

28. Greenhalgh T, Helman C, Chowdhury AM. Health beliefs and folk models of diabetes in British Bangladeshis: a qualitative study. BMJ 1998; 316(7136): 978-983.

29. Brown K, Avis M, Hubbard M. Health beliefs of African-Caribbean people with type 2 diabetes: a qualitative study. Br J Gen Pract 2007; 57(539): 461-469.

30. Bean D, Cundy T, Petrie KJ. Ethnic differences in illness perception, selfefficacy and diabetes self-care. Psychology and Health 2007; 22(7): 787-811.

31. Burnside J, Wells W, Smith M, et al. Education for the prevention of foot ulcers: views of those with neuropathy. The Diabetic Foot 2007; 10(1): 17-23

32. Cohen MZ, Tripp-Reimer T, Smith C, et al. Explanatory models of diabetes: patient practitioner variation. Soc Sci Med 1994; 38(1): 59-66

33. Murphy E, Kinmonth AL. No symptoms, no problem? Patients' understandings of non-insulin dependent diabetes. Fam Pract 1995; 12(2): 184-192.

34. Horowitz CR, Rein SB, Leventhal H. A story of maladies, misconceptions and mishaps: effective management of heart failure. Soc Sci Med 2004; 58(3): 631-643.

35. Vileikyte L, Gonzalez JS, Leventhal H, et al. Patient Interpretation of Neuropathy (PIN) questionnaire: an instrument for assessment of cognitive and emotional factors associated with foot self-care. Diabetes Care 2006; 29(12): 2617-2624.

36. Britten N. Lay views of drugs and medicines: orthodox and unorthodox accounts. In: Williams SJ, Calnan M (eds). Modern medicine. Lay perspectives and experiences. London: UCL Press, 1996: 48-73.

37. Campbell R, Pound P, Pope C, et al. Evaluating meta-ethnography: a synthesis of qualitative research on lay experiences of diabetes and diabetes care. Soc Sci Med 2003; 56(4): 671-684.

38. Johnson M, Newton P, Jiwa M, Goyder E. Meeting the educational needs of people at risk of diabetes-related amputations: a vignette study with patients and professionals. Health Expect 2005; 8(4): 324-333.

39. Kleinman A, Eisenberg L, Good B. Culture, illness, and care: clinical lessons from anthropologic and cross-cultural research. Ann Intern Med 1978; 88(2): 251-258.

40. Funnell MM, Anderson RM. Empowerment and self-management of diabetes. Clin Diabetes 2004; 22(3): 123-127.

41. Horne R, Price D, Cleland J, et al. Can asthma control be improved by understanding the patient's perspective? BMC Pulm Med 2007; 7: 8 DOI:10.1186/1471-2466-7-8.

42. De Ridder DT, Theunissen NC, van Dulmen SM. Does training general practitioners to elicit patients' illness representations and action plans influence their communication as a whole? Patient Educ Couns 2007; 66(3): 327-336.

43. Kinmonth AL, Woodcock A, Griffin S, et al. Randomised controlled trial of patient centred care of diabetes in general practice: impact on current wellbeing and future disease risk. The Diabetes Care From Diagnosis Research Team. BMJ 1998; 317(7167): 1202-1208.

44. Michie S, Miles J, Weinman J. Patient-centredness in chronic illness: what is it and does it matter? Patient Educ Couns 2003; 51(3): 197-206.

45. National Institute for Clinical Excellence. Prevention and management of foot problems in people with type 2 diabetes. Understanding NICE guidance - information for people with type 2 diabetes, their families and carers, and the public. London: NICE, 2004 


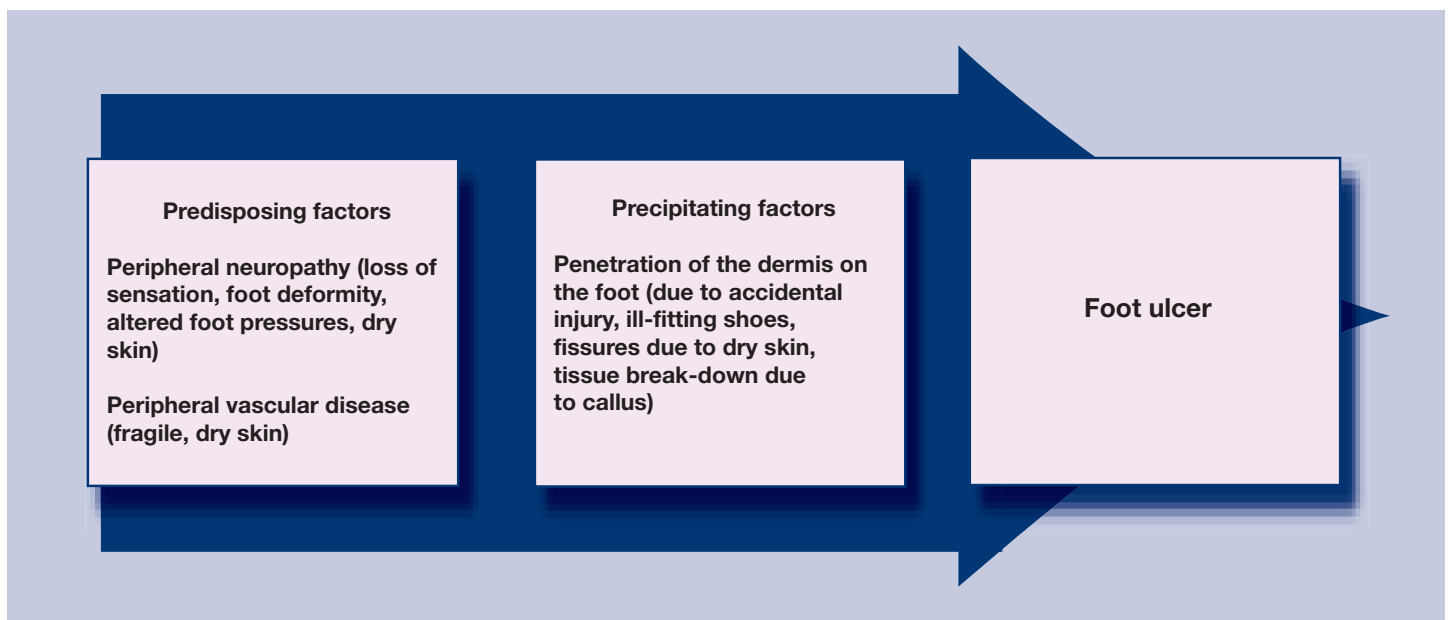

Appendix 1. Predisposing and precipitating risk factors for foot ulceration.

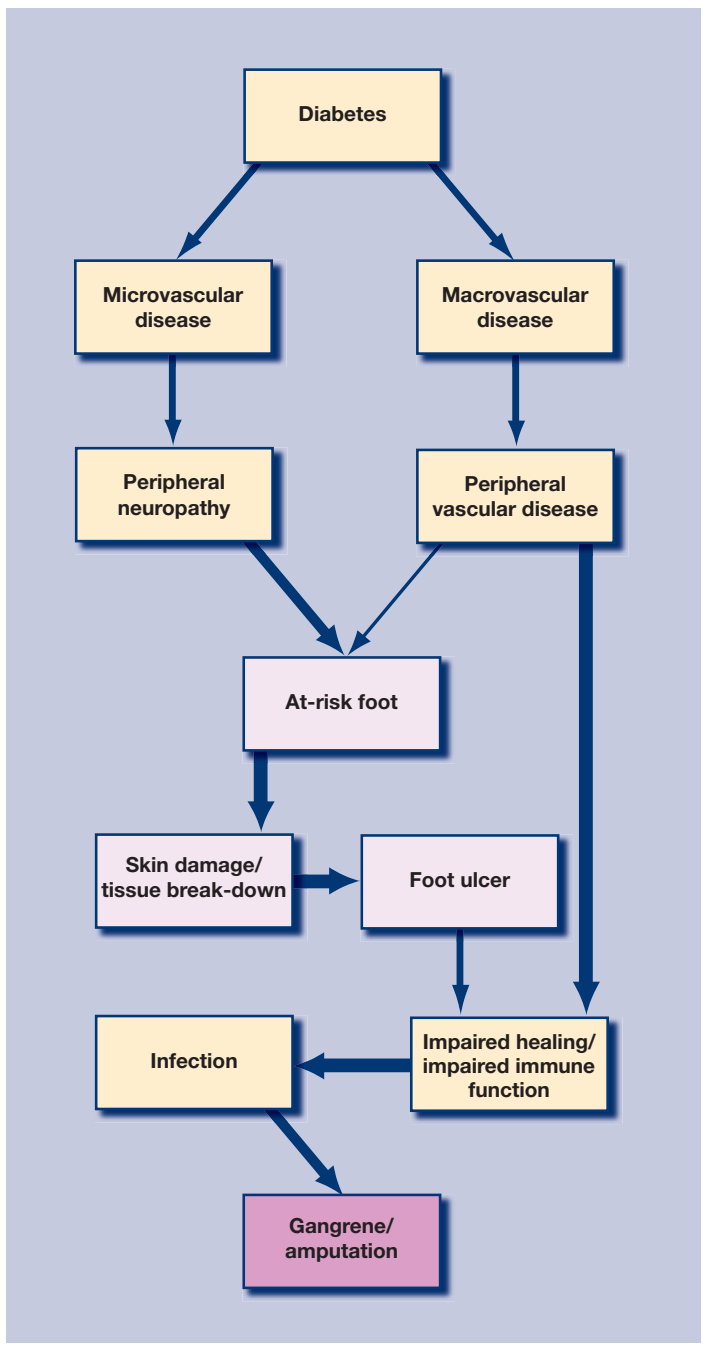

Appendix 2. Medical model ${ }^{\mathrm{a}}$ of lower-limb complications in diabetes.

${ }^{\text {a }}$ The model is a simplified version of the most common pathway to amputation in patients with diabetes. ${ }^{1,9-11}$

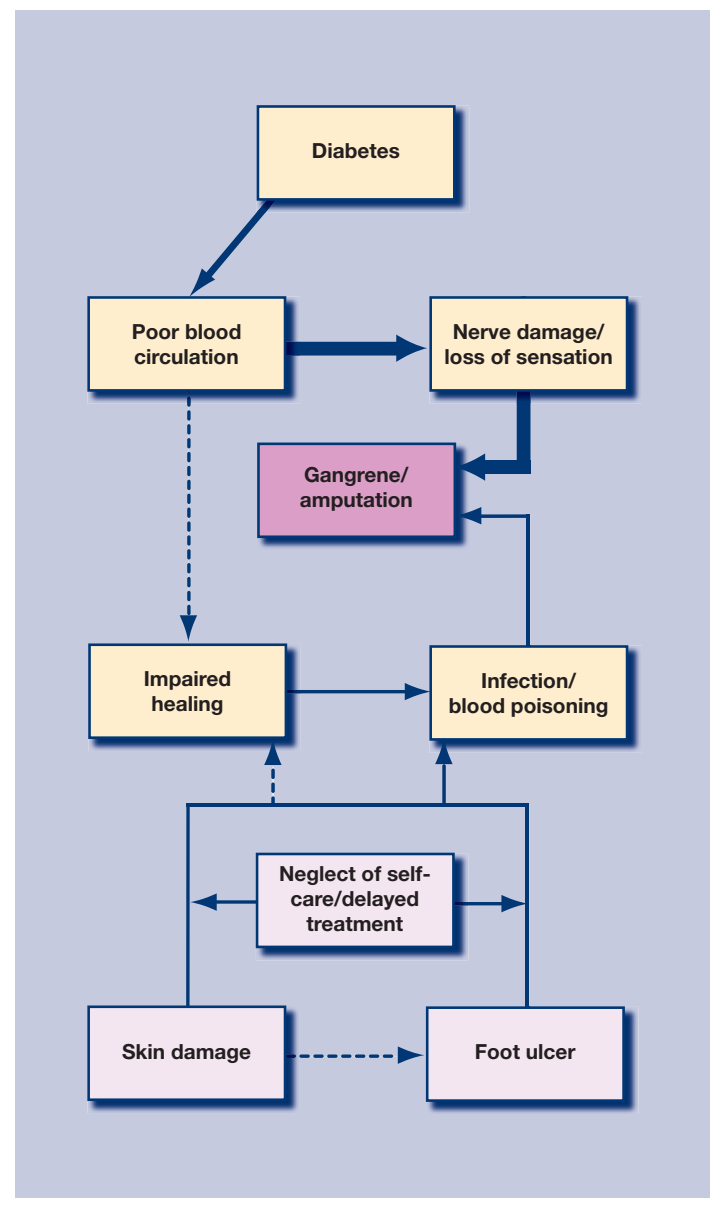

Appendix 3. Participants' model ${ }^{\mathrm{a}}$ of lower limb complications in diabetes.

'The model is based on participants' interpretation of the main causes of amputation in diabetes. The thick arrows at the top indicate the pathway to amputation thought to be the most common. The pathway in the lower half was thought to be rare. The broken lines indicate that very few participants mentioned the connection. 


\section{Appendix 4. Points to clarify with patients to avoid common} misconceptions about foot health and ulceration. ${ }^{\mathrm{a}}$

Q: What is a diabetic foot ulcer?

A: The word ulcer is derived from the latin word ulcus which means sore or wound. The generally accepted definition of a diabetic foot ulcer is a penetration of the skin below the ankle in a person with diabetes, irrespective of size and duration.

Q: What is the greatest risk to foot health?

A: Wounds on the feet, however small, pose a risk because they could be the entry point for infection. It is therefore important to protect the feet from any skin damage.

Q: Can infection occur if the feet are clean?

A: Bacteria can enter through a small opening in the skin, even if foot hygiene is excellent. Infection can occur very quickly in a person with diabetes and may be difficult to treat.

Q: What happens if the blood supply to the feet is affected?

A: Diabetes can damage blood vessels in the legs and feet. This can result in difficulties with the healing of even small sores on the feet. If infection occurs treatment with antibiotic medication may not be effective. It is therefore important to avoid any risk of skin damage, for example by walking around without footwear.

Q: Is numbness caused by poor blood supply to the feet?

A: Numbness in the feet does not indicate poor blood supply or that tissue is dying and at risk of becoming gangrenous. However, it does mean that some sensitivity is lost and an injury may not be painful. Any break in the skin is potentially serious, even if it is not painful. The feet should always be well protected and inspected for any changes on a daily basis.

${ }^{a}$ The questions are based on areas where participants were found to have uncertainties or misunderstandings. The answers are based on the guidance for patients issued by NICE, ${ }^{45}$ medical textbooks, ${ }^{9,10}$ and input from clinicians. However, the topics and answers are not exhaustive and should not replace clinical guidelines. 